\title{
Exploring Disruptive Thinking Possibilities in Construction and Engineering
}

Sittimont Kanjanabootra ${ }^{1 *}$

\begin{abstract}
Innovation adoption in construction and engineering projects is often claimed to be problematic and slow. Traditional analysis of innovation adoption is grounded in evidence-based practice and financial risk analysis. This has the effect of making innovation development in construction rarely able to disrupt industry. Innovation tends to occur in a drip feed like manner resulting in incremental and slower adoption. This is perceived as a problem for the construction industry. This paper uses the concept of Disruptive Thinking to examine a potential frame of reference for construction practitioners in their work and how they approach innovation adoption. The research uses interviews producing personal stories with professionals working on construction and engineering projects. The research shows that there is some evidence of use of disruptive mindsets by construction and engineering professionals, resulting in disruptive practice in certain sectors, not in the construction industry as a whole. The paper concludes that Disruptive Thinking is a starting point, and vehicle that can lead practitioners to more readily adopt innovation. Disruptive thinking can be a means to adoption when the mindset of evidence-based practice can be infiltrated.
\end{abstract}

\section{Keywords}

Construction, Innovation, Disruption Theory, Disruptive Thinking

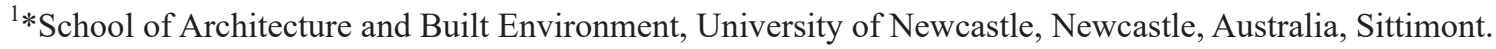
kanjanabootra@newcastle.edu.au (Corresponding Author) 


\section{Introduction}

Research on management of engineering and construction projects is not always reflective of a larger economic dynamic. Engineering and construction projects, or parts of those projects, are driven by a complex integration of various stakeholder business strategies. In construction, innovation adoption has been shown to be less effective than desired (Akintoye and Main, 2012; Allen and Shakantu, 2016; Eriksson and Kadefors, 2015; Murphy et al., 2015; Winch, 2003; Reichstein et al., 2005; Rigby et al., 2012; Sergeeva, 2014; Slaughter, 1998,2000) and change has been slow. This paper re-examines the problem about reluctance to innovate in construction but from an alternative perspective.

Typically the construction literature has shown that there is inconclusive evidence about the extent of innovation adoption in construction and a lack of knowledge about the kind of innovations and how were they generated; about how innovations are interrelated and how new they really are to the company, the industry, or the world; and about who initiated them (Brockmann et al., 2016). The research also shows that there is a high propensity for innovation failure in construction (Murphy et al., 2015), with risk aversion having an important impact on propensity to adopt innovation (Rose and Manley, 2014). In addition, Winch (2014) argues that construction and engineering projects are episodic, indicative of periods of uptake and then benign periods where other pressures negate innovation. Winch also argues that larger construction organisations are often decentralised which, in effect, fragments opportunities to innovate, as there is no continuity.

There is a rich literature in the Business domain which implies that innovation can be viewed from an alternative perspective; that is, through disruption (O'Reilly III and Tushman, 2016; Christensen, 2013). To von Mutius (2017) Disruptive Thinking means the ability to think in terms of breaks with convention and non-linear developments - and to accept that these will not merely be a passing trend. Williams (2015) defines Disruptive Thinking as a way of thinking that turns consumer expectations upside down and takes an industry into its next generation. The extant construction and project management literature has little researched the impact that Disruptive Thinking might have on willingness to adopt innovation. This paper then investigates the potential of Disruptive Thinking as one way to view business decisions about innovations in engineering, construction and project management and evaluate their potential impact on innovation acceptance. This research aims to better understand the ways construction and engineering professionals think about innovation using a lens of Disruptive Thinking to make sense of what their stories tell. The intent is not to produce the normative list of drivers and barriers to innovation adoption in C\&E. So the researcher asks: To what extent is a Disruptive Thinking mindset present in professionals in the construction and engineering industry and what affects the use of Disruptive Thinking by those professionals in innovation adoption?

\section{Literature Review}

\section{Definition of Innovation}

Innovation is defined variously. Schumpeter (1947) initial conceptualisation of innovation was the practice or implementation of novel ideas (inventions). Schumpeter described innovation as an historic and irreversible change in the way of doing things and was concerned about the economic impact rather than the idea itself. However, Winch (1998) developed the notion of innovation in construction as a dynamic process situated in a complex systems domain. Additionally, Innovation in construction has also been defined as the integration of non-trivial ideas capable of generating positive changes that increase a company's competitiveness (Pellicer et al., 2017). More comprehensively, Slaughter (1998) defined innovation as any, or combinations, of incremental, architectural, modular, systematic and radical forms which, it has been argued, represented the extent to which an innovation deviates in function from standard practice; and the extent of integration of the innovation with other systems/processes. This differentiation of ideas about what innovation is, is common throughout the construction and engineering literature. One 
example of this relates to how various authors have classified innovation.

Radical innovation is defined as a transformational breakthrough in science or technology which often creates great difficulties for established firms and can be the basis for the redefinition of an entire industry (Dewar and Dutton, 1986). Alternatively, innovation can also be defined as technical, largely product innovations (Gann and Salter, 2000) or organisational, as changes to a business or organisation, or implementation of new corporate strategies (Lloyd-walker et al., 2014; OECD, 2005). Adding to this multiplicity of definition, Boer and During (2001) define innovation as both the introduction of advanced management techniques and process innovation, which Bygballe and Ingemansson (2014) add to as new activity links in which activities are co-ordinated in a new way, across firms' boundaries. The research literature in construction and engineering, reviewed in the following section maintains these differential perspectives. This paper aims to see if using a disruptive perception of innovation might be a means of clarification, and a means to address the challenges of the impacts of inertia, financial constrain, risk aversion, the episodic nature of projects etc, on innovation adoption in construction and engineering.

\section{Adoption of Innovation in Construction and Engineering}

Innovation adoption research in construction and engineering has identified contextual explanation about why adoption is often less than expected. The research identifies that the paucity of innovation uptake in construction results from:

- a lack of in-house skills, financial constraints, associated industries, and the culture of the construction industry and attitudes of clients and manufacturers (Blayse and Manley, 2004);

- from consultants such as engineers and architects (Shelton et al., 2016);

- from the complexity (Wisdom et al., 2014), and the loosely coupled nature of the construction industry and relationships between individuals and firms within the industry and between the industry and external parties, including the demands of clients (Blayse and Manley, 2004; Dubois and Gadde, 2002; Pellicer et al., 2014);

- from the construction industry favouring short-term productivity, hampering innovation and learning (Blayse and Manley, 2004; Dubois and Gadde, 2002); and

- from effects and constraints of regulations/ standards (Blayse and Manley, 2004).

Other research has adopted a more constructive appraisal of what might facilitate better / faster innovation uptake in construction and engineering. These facilitating factors include a requirement that construction firms have suitable business strategies to break the mould and enable systemic innovations (Hall et al., 2020) and that construction firms need to respond to innovation to sustain competitive advantage and capture the derived short-term profits as new or altered markets emerge (Gajendran et al., 2014); that "climate innovation" and "innovation value-fit" are significant factors to 'make or break' innovation implementation success in projects (Mollaoglu-Korkmaz et al., 2014) and the need to solve technical problems (Pellicer et al., 2014); that there can be an organisational "innovation narrative" where organisational activities become labelled as innovations through the process of collective inter-subjectivity and have been used in those organisations as a tool to establish and maintain the legitimacy of the organisation's innovation (Sergeeva, 2014); that there is a clear understanding that each innovation needs different skills, resources, and cultures to encourage adoption (Yusof et al., 2014); that incentive motivation for an innovation implementation in infrastructure projects is perceived as high rather than low stakes (Eriksson and Kadefors, 2015); and that there is clear leadership (Ling, 2003; Nam and Tatum, 1997; Pellicer et al., 2014; Weidman et al., 2016)

There is also a detailed literature on innovation adoption outside of construction and engineering which identified key drivers and inhibitors in innovation adoption across many domains (Bogers et al., 2017; Wisdom et al., 2014). The key drivers 
for innovation adoption identified in that research include: desire for improved competitiveness (Frambach and Schillewaert, 2002); working within government policy requirements (Aarons et al., 2011; Mitchell et al., 2010; Rogers, 2010); organisational capacity to take on innovation (Aarons et al., 2011; Feldstein and Glasgow, 2008; Frambach and Schillewaert, 2002); organisational commitment (Feldstein and Glasgow, 2008; Mitchell et al., 2010); cost efficacy, workability and risk associated with the innovation (Wisdom et al., 2014); and the characteristics of the innovation itself (Graham and Logan, 2004). These drivers bear a marked similarity to those identified in the construction and engineering literature. However, the literature in the business domain extends beyond the above and focuses more on the bureaucratic perspective within the organisation and their strategic thinking.

Failure to adopt innovation is argued to derive from a situation where incumbent firms have a particular way of managing inward-looking hierarchical bureaucracy that makes them prone to fail at innovation (Denning, 2015; King and Baatartogtokh, 2015; Sampere, 2017). This problem is seen as significant when considering that out of 20000 new products released between 2012 and 2016, only $0.46 \%$ had sales in excess of $\$ 50$ million in the first year and sustained sales in year 2 (Christensen et al., 2016). The inwardlooking hierarchical bureaucracy noted by Denning (2015) is most often associated with adoption of business strategy (Lansley, 1987; Oyewobi et al., 2016; Porter, 2008; Sage et al., 2012). In exploring innovation in business Christensen (2006) argues that innovations, are often hampered by the rigidity of strategy which in part can slow down its uptake, because strategy determines the mindset of decision-makers. Bekefi and Epstein (2017) propose that there is an innovation paradox that results from the business adoption of strategy and strategic management. They argue that 'the aggressive pursuit of operational excellence and incremental innovation crowds out the possibility of creating what we really want - breakthrough innovation'. This breakthrough innovation is hampered by the focus in strategy on the immediate and rigid reporting practices rather than on prospects and futures. In construction and engineering numerous innovations have been or are being adopted because they are perceived to incur strategic advantages through cost saving, improved efficiency or the gaining of competitive advantage. These include Building Information Modelling (BIM) (Allen and Shakantu, 2016) and Offsite Manufacturing (OSM) (Ozorhon et al., 2014); the use of drones (Irizarry and Costa, 2016; Li and Liu, 2019; Motawa and Kardakou, 2018), the adoption of Big Data analytics (Atuahene et al., 2020), or the application of Crypto-Economic application such as Blockchain (Hunhevicz and Hall, 2020). However, these examples of research on innovation in construction and engineering have focused on the outcomes rather than what was happening leading to decisions about adoption. This review of the existing literature has only provided lists of drivers and inhibitors to adoption in construction and engineering rather than an understanding of what leads to innovation adoption in the first place. Each of these inhibitors creates challenges to the construction and engineering industry, to the leadership of organisation within those industries, and to the professionals who design, manage and implement the construction and engineering projects. That literature has not satisfactorily yet found ideal solutions to those challenges. Is there an approach then, where we can better understand the mindset of construction and engineering professionals as they think about innovation adoption? One possible answer to this question might lie in other research where the focus is on disruption and Disruptive Thinking.

\section{Disruption Theory and Disruptive Thinking}

Christensen (2006, 2013) and Christensen and others (Christensen et al., 2001; Christensen et al., 2006) offer, perhaps, one perspective that may assist in resolving these problems of inertia in innovation adoption in construction and engineering. They argue that really effective and highly successful innovations are most often, but not always, disruptors. Those innovations, they argue, change the nature of the marketplace. In effect, they change the power relations in a market and subsequently affect demand, supply and price. For engineering and construction project management, disruption

Engineering Project Organization Journal

(C) 2021 Engineering Project Organization Society www.epossociety.org 
might become an essential improvement facilitator as project management is becoming more difficult with increased competition, shorter product and service life cycles, more constrained budgets and increasing complexity (Hall, 2012). Hall (2012) also argues that new techniques/innovations applied in project management are not being adopted readily.

Innovations are argued in Disruption Theory to have significant impact in economic markets, affecting price, demand and profit. They can drive change in work processes, in efficiency, in business time and offer opportunities for increased productivity in almost all industries. Christensen (2006) argues that a disruptive innovation is one that creates a new market and new value network. Eventually the innovation disrupts an existing market and value network, displacing established market leading firms, products, services and alliances, often at a cheaper price. However, the application of Disruption Theory as defined by Christensen is constrained. Christensen describes disruption as a process by which a smaller company (with fewer resources) is able to challenge a larger more well-established company (Christensen et al., 2016). This can happen because, over time, the larger company tends to focus on their most profitable products and customer base. This creates overlooked market segments in which the smaller company can gain entry, eventually moving upmarket and winning over customers from the larger company. From this description, we see two requirements for an innovation to be considered "disruptive": (1) the innovation originates in low-end markets (ie, previously ignored or not otherwise targeted markets) or completely new markets, and (2) the innovation does not obtain widespread adoption with customers until the quality (eg, utility, perceived benefit, etc.) matches competing products. King and Baatartogtokh (2015) analysed 77 noted 'disruption innovations' and found that only 9\% actually met Christensen's criteria. Disruption as a concept in business then has developed beyond the constraints of Christensen's construct. Dynamic change, Christensen et al. (2016) argue in their definition, results from innovation adoption filling new spaces in the marketplace, in this context of construction and engineering projects. Disruptive innovations ultimately replace the status quo, and shift market power, albeit not necessarily, others have argued, within the constraints of Christensen's Disruption Theory.

Others (Fukiyama, 1999; Markides (2006,2013); Raynor, 2011) argue that disruption creates some form of chaos and represent a way of thinking, rather than something existing within a singular construct. That chaos comes from an innovation causing perspectives unseen before, disrupting the norms, changing behaviours which change and continue to innovate in alternative directions to what exists. Above all disruptors are often seen as successful innovations. However, do these innovations act at a more substantive level, providing opportunities to also shift market power? It is a disruption that it is believed will change, unsettle, create chaos and disturbance in the normative patterns of power. In the construction and engineering literature on innovation (reviewed above) there is little evidence of innovation being perceived as "unsettling" or "creating chaos" and therefore, "disturbing normative patterns of power" or "shifting markets". Rather that literature demonstrates slow and incremental processes of innovation adoption. Typically, construction and engineering adoption is a diffusion process and the dynamics mindsets argued for in Disruption Theory are rarely if ever, existant.

There are also severe critics of Christensen and his acolytes. Sampere (2017) argues that Schumpeter had already identified the accrual of short-term profit (Schumpeterianrent)(Schumpeter, 1942) as a result of innovation adoptions disrupting existing markets, a point also noted in an analysis of innovation in construction by Gajendran et al. (2014). Chistensen, critics argue, offers little that is new. They argue that such disruption is quite uncommon and that Disruption Theory per se does not actually address what really happens in business (King and Baatartogtokh, 2015; Mui and Carroll, 2013). Sampere (2017) argues there are in fact three different forms of disruption. The first is the limited form described by Christensen which begins bottom up and is ignored by their competitors to their detriment. The second are those described by King and Baatartogtokh (2015). 
These include accepted disruptors like Tesla and Uber which have changed industries but not in ways that parallel Christensen's theory. Rather they imply Disruptive Thinking to challenge the status quo in an industry without necessarily being driven from the 'bottom-up' or that matches existing products. However, according to Christensen these are not disruptors at all because they do not meet his limited criteria for a disruptor as they target premium customers, and competitors still don't react. Sampere (2017) adds a third type where high-end customers will react to the disruptor, but that response won't be effective because the new company/innovation is in a competitive place that the existing companies or innovative processes cannot reach. Skype international is an excellent example as the telecom companies have no strategy and no legal basis to compete with the Skype model. Whilst many innovations do not actually meet the classic criteria for classification as a disruptor, disruption is actually happening on a massive, ever increasing scale. This disruption is happening through application of what is defined as Disruptive Thinking, from new start-ups pushing cheaper, but high quality, competitive products and processes into existing marketplaces. It is also happening from established businesses introducing premium-end products, either competing against existing products or creating new marketplaces and demand, or through adoption of technological innovations that are designed to improve business process. These critiques of Christensen's Theory of Disruption have developed into a broader, more flexible domain defined as Disruptive Thinking.

Disruptive Thinking, it is argued, can offer a broader understanding of the impact of innovation (von Mutius, 2017). It can also give a clearer understanding of how innovation uptake can become more widely spread and perhaps faster. Disruptive Thinking offers another potential lens to examine innovation impact. What is proposed here is not a typology of disruption types but a framework and set of principles that should define any disruptor. Disruptive Thinking has been used as a lens to better understand why the acceptance of innovation is often challenged by the status quo or the conservatism inherent in the marketplace (Fornstedt et al., 2015) which often leads to 'drip feed' up-take of innovation (incrementalism) in engineering and construction. Disruptive Thinking offers a different perspective about innovation and adoption where the focus is not on success factors or barriers. Rather, the focus is on the innovation itself, how users are thinking about that innovation, and what that innovation creates, offers, impacts, and disrupts. von Mutius (2017, p. 9) proposes five principles that define Disruptive Thinking

- Disruptive Thinking is thinking that grows with the complex requirements of our time. It is lateral thinking without safety rails. [complexity]

- Disruptive Thinking is a realistic way of approaching the future, one that actively factors in the possibility of disturbances rather than excluding them. [realistic approach]

- Disruptive Thinking is a bilingual thinking; it is at home in two worlds. It reckons with uncertainty and makes the inconsistencies productive. [uncertainty]

- Disruptive Thinking is an "operating system with a difference" for organisations facing digital transformation and standing on the precipice of the creative revolution. [difference]

- Disruptive Thinking fosters innovation potential and strengthens social responsibility. [social responsibility]. (This principle wasn't applied in this research as the focus in the existing research literature has been on economic, business and technology. The application of this principle will be engaged with in future research.)

Disruptive thinking is an integrative mindset challenging normative thinking seeking new possibilities, reckoning uncertainty, and recognising potential. These principles frame a mindset for individuals or organisations to adopt as part of their personal or organisation domain which inform their decision making about innovation. Disruptive thinking can be practiced by an individual or professional or within the norms of an organisational culture (Flamholtz and Randle, 2014), with common values and beliefs, and behavioural practice. In either case the thinking reflects inherent 
complexity, realism, uncertainty and difference. With reference to the often cited examples of innovation in construction, referred to above, BIM, OSM, drones, Big Data and Blockchain etc., none match the strict criteria of Christensen's theory. However, whilst BIM, OSM, drones, Big Data and Blockchain etc. can represent innovation as products and / or process, these innovations do represent new ways of doing things. It can be argued that they do derive from some degree of Disruptive Thinking as a mindset. They demonstrate the ability to think in terms of breaking with convention and non-linear developments - and over time are demonstrating acceptance that these innovations will not merely be a passing trend. These innovations suggest thinking beyond the traditional norms in construction and engineering. They represent possibility and recognise potential.

Burt (2007) uses scenario methodology to examine the impacts of disruptions and discontinuities that can emerge from new technologies in engineering projects in the UK power industry. Their focus was on the systemic rather than business effects, highlighting the impacts of embedded technologies (status quo) as inhibitors to managerial vision. However, they also applied Disruptive Thinking, highlighting that new disruptive products emerging in that industry were often, smaller, simpler and cheaper, and were developed initially in insignificant marketplaces. These innovations were shown to be highly likely to succeed and be implemented but faced the same degree of inertia to innovation adoption recognised in existing research. However, some were adopted, and significant changes happened in the marketplaces in that industry. The change was occurring in one small market system within the larger power engineering market, illustrating the fragmented nature of construction and engineering being composed of multiple small systems within the larger whole. Burt (2007) argues that the success of these innovations depended on the direct impact of changes on consumers where they were offered better perceived value for them. In the same way, changes to electricity power provision is responding to initial small changes and then fast growth. It is being driven by consumer power and a 'change' mindset. Burt shows the application of Disruptive Thinking as a process can impact on the mindset of practitioners' decisions about innovation adoption.

Disruption Theory and disruptive thinking have become significant in the Business literature as there is a consensus both that innovation that is disruptive and that innovations which derive from disruptive thinking are very successful in producing changed business behaviours, changed demand for products and producing changed marketplaces (Fukiyama, 1999; Gajendran et al., 2014; Hall et al., 2020; King and Baatartogtokh, 2015; Markides, 2006; Christensen, 2013; Raynor, 2011; Sampere, 2017). Trying to understand the use of disruptive thinking in construction and engineering then potentially offers a potential means to achieve the same success.

This paper explores if the applicability of Disruptive Thinking in practitioners' mindsets can act as a means to understand construction professionals' approach to innovation adoption and to uncover answers to the research question: To what extent is a Disruptive Thinking mindset present in professionals in the construction and engineering industry and what affects the use of Disruptive Thinking by those professionals in innovation adoption?

\section{Research Methodology}

This research is exploratory (Fellows and Liu, 2015), trying to understand if Disruptive Thinking can assist professionals in the engineering and construction industries to improve our understanding of innovation adoption. This research uses storytelling by construction professionals (Sergeeva and Trifilova, 2018) and an analysis of text (Geertz, 1973; Miller et al., 2015). This type of research reports narratives, most often as vignettes (Stake, 2013), often as exemplars of what has, and is happening in a specific domain. The purpose of the interview is to allow each participant to explain the situation in their own words (Holt and Edwards, 2013). This can be used as a means to bring readers to experience the dilemmas faced by domain experts (Lee et al., 2015). Most often this type of research is done as case studies (Yin, 1994). However, the intention here was to understand perceptions of professionals across 
many organisations, each with multiple case experience. Each conversation between participant and researcher was recorded and that conversation was open-ended, focusing on the respondent's views about innovation in construction and their understanding of what innovations are successful and why. The conversations sought to expose construction professionals' perspectives on innovation and assist in better understanding of how they viewed them (Katsonis and Botros, 2015). The conversations also elicited what they understood about why some innovations get adopted faster and more widely than others and even why seemingly good ideas and new innovations are not adopted.

Twenty-nine (29) construction professionals were interviewed in this research project. Purposive selection (Ellett et al., 2002) was used to identify these construction professionals because the researcher needed people from whom they could substantially learn about their experience as it relates to innovation in practice (Polkinghorne, 2005). Each participant in the study was initially approached from professional contacts of the researcher an accepted research method used in this type of research (Chan, 2013; Coyne, 1997) and application of further recommendations through snowballing (Baltar and Brunet, 2012; Biernacki and Waldorf, 1981; Emerson, 2015). The twentynine construction professionals included eleven (11) Engineers (E1 - E11), three (3) Architects (A1-A3), seven (7) building company Directors (D1-D7), four (4) property developers (PD1-PD4) and four (4) quantity surveyors (QS1-QS4). All 29 of the construction professionals are experienced in the construction industry, some in Australia, some in Thailand and some in the UK. For consistency, the definitions of 'professional' by Engineers Australia and Thailand, the Australian Institute of Architects and the Australian Institute of Quantity Surveyors are used: 'a professional holds a 4 year university degree or equivalent, and minimum of five years acceptable work experience at the level of Professional Engineer (Australian Institute of Architects, 2017; Australian Institute of Quantity Surveyors, 2017; Engineering Australia, 2017; AIB, 2017).

The level of research objectivity is often a problem in qualitative research (Denzin and Lincoln, 1994). Stories tell the perceptions and truths of those being interviewed. The conversations they have as part of the research are their own. It is their reality and their objectivity. Qualitative research seeks to tell the stories of others and as Kanjanabootra and Corbitt, 2016 notes 'the narrative provides meaning, context, and perspective for the subject's predicament. It defines how, why, and in what way he or she is thinking'. Löwstedt (2015) and Wolcott (1999) argue that stories and narrative can enhance and deepen our understanding of practice and action referred to in the story. In this research the statements of the respondents are accepted as their own perspective and the generalisations made in the paper are only made when there is a tendency for respondents to repeat or reiterate what others have said.

To seek answers to the research question the key tenets of von Mutius's principles of Disruptive Thinking were used to construct a set of questions asked of each participant. The questions asked are listed below with the applicable principle(s) of DT in brackets [].

- Can you tell me about a project you have been involved in or project managed where an innovation was proposed as part of the project (that innovation might be a new product, new material, or new process or new method of construction)? [difference], [realistic approach].

- Was this decision part of your company's business strategy? Please explain. [realistic approach]

- In your experience did/will this innovation overtake the performance characteristics of existing offerings? Please explain. [realistic approach] [complexity]

- Will the offering better satisfy customers' future needs? Please explain. [complexity] [uncertainty]

- Do you think that you and/or the builders, professionals involved, have the right skills, culture and capacity to rapidly execute on the idea? Please explain. [realistic approach]

- Is/was the existing business the right place to scale-up the disruptive offering? Please explain. [difference] [realistic approach] 
- Do you think that getting quick wins with a new innovation to prove the potential of the offering, would be significant? Please explain. [difference], [realistic approach]

- Was the decision to try the innovation driven by the demands and needs of customers, and/or the requirements of governments and/or standards authorities, or the accepted status quo of those managing engineering projects? Please explain. [realistic approach] [complexity], [uncertainty]

The stories of each of the construction professionals were transcribed, read and reread to identify common and differentiated outcomes from their perspectives, and different domains of experience. NVivo and then thematic coding both assisted the researcher to identify key issues about innovation in construction (Fereday and Muir-Cochrane, 2006). The coding applied a series of terms and contextual similarities derived from the principles of Disruptive Thinking (DT) von Mutius (2017) listed above. The key codes applied to the text transcribed from the interviews in this research process were: complex requirements, realistic approach, uncertainty and difference. The text examples were then collected according to the principles to look for similarities and differences in the extent to which each was relevant. The outcomes of the coding are summarised in Table 1.

\section{Interview Analysis Results and Discussion}

The emergent themes from the stories of the professionals interviewed for this research are shown in Table 1. Each is then discussed in detail in the sections following.

\section{1) Accepting Status Quo}

Projects in the construction and engineering industries comprise many stakeholders. The respondents in this research noted that in their experience almost all innovations, products, materials or processes benefit only a few stakeholders, 'maybe even one', on many occasions, in any project. Therefore, other stakeholders are not interested to join forces with those wanting to adopt. From the perspective of the interviewees, this creates two problems. Firstly, some stakeholders such as owners/property developers always have a clear business goal which is to make a timely profit at the end of construction project. This is commonly accepted as the status quo. Therefore, some types of innovations, the respondents stated, which could potentially realise benefits in the long run from return of investment, often take too long. Subsequently the innovations are ignored even if the end users may want to use, or could benefit from, the innovation. One of the respondents, a Quantity Surveyor, in reference to the use of BIM in QS process as an innovation (QS1), said:

I don't know whether the Australian construction industry have that innovation disruptive culture, because we are kind of ... we are typically have done it that way. We are stuck in our way and don't want to change.

This problem, it can be suggested, reflects a conservative mindset towards innovation as noted by both Fornstedt et al. (2015) and Burt (2007). The innovation does not change the way that the processes have been done. These innovations do not 'disrupt' globally, rather they are local, and as the respondents noted, even if innovations which happen in similar contexts are adopted in some way, the process is slow and incremental. This is the way that the construction industry accepts the status quo and can be considered as a hindrance to adoption of a disruptive mindset.

Secondly, in typical construction projects the specific end users sometimes have not been identified during the design stage. For example, one respondent (PD1) noted that in office building construction projects, owners or properties developers often want to adopt new innovation products such as a high-quality building management system. However, this innovation might push up the leasing price significantly, and as a result the typical office tenants might find it as "an over-specification". Another classic 


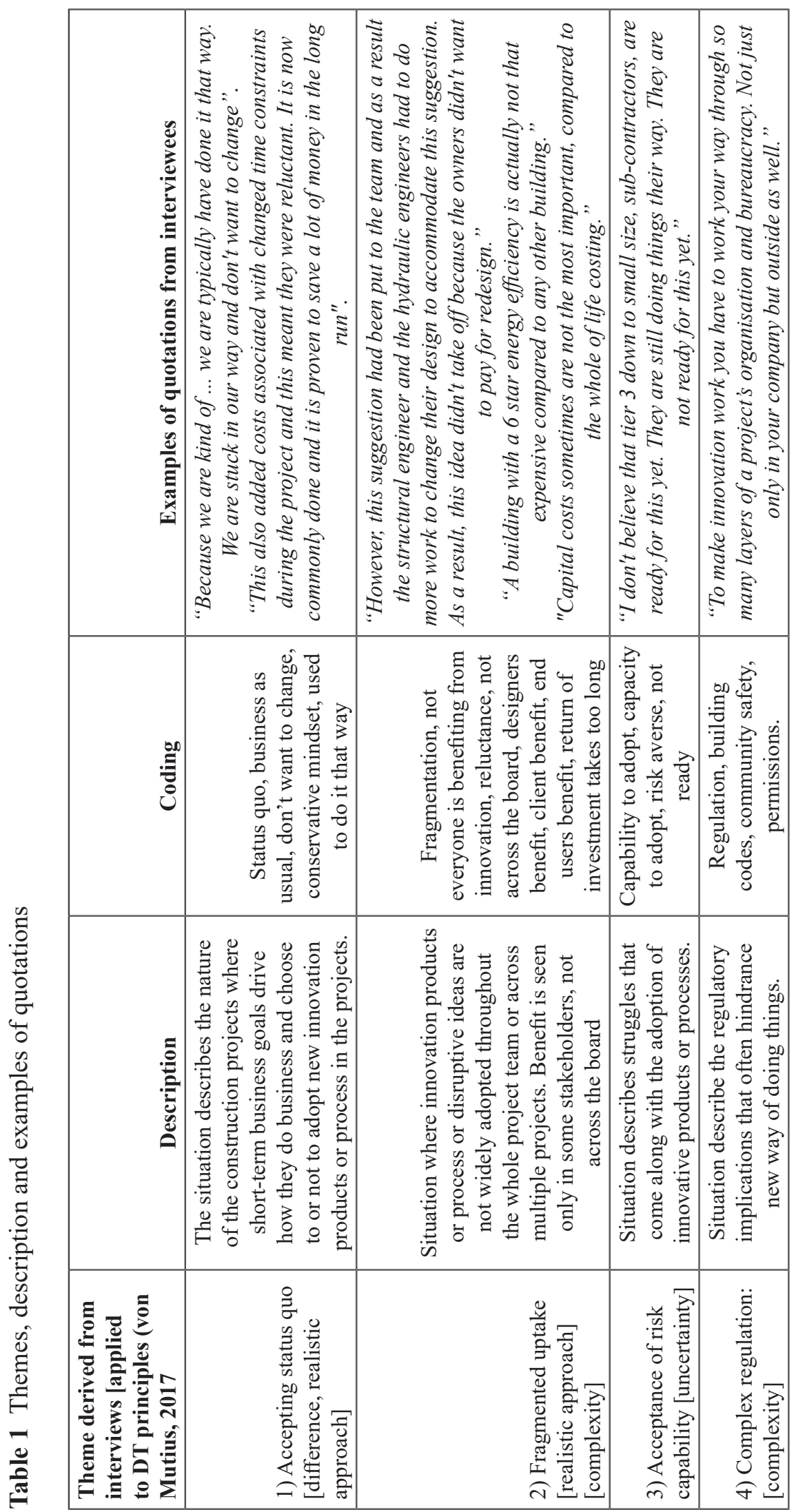

Engineering Project Organization Journal

(C) 2021 Engineering Project Organization Society www.epossociety.org 
example has happened in BIM adoption (Weidman et al., 2016; Wong and Fan, 2013). This was also noted by some of the respondents (A1, E3 and D2). For construction stakeholders to adopt BIM, the project team might be required to consider different procurement methods which can facilitate BIM adoption. However, not all construction stakeholders have the ability, or the intent, to adjust their business practices to suit some of the specific requirements of BIM. Therefore, only a small portion of the industry are capable of, or flexible enough to do so. This means that 'the rest have been left behind' and as a result BIM is still not widely used, especially in SMEs (Brewer et al., 2012).

\section{2) Fragmented Uptake}

End users often do not see the benefits of the proposed innovation, especially, if the innovation is a process (not product). In some construction projects, the interviewees noted, different construction techniques have been used to address site access and project time constraints. As a result, the project cost is higher than common construction methods. Another architect respondent (A2) said:

there was a particular project where one stakeholder had a water tank (product and design as an innovation) underneath in a void in one part of the building. It is not an innovation now but 30 years ago, it was uncommon. The intention was to reuse rainwater for the landscape. However, this suggestion had been put to the team and as a result the structural engineer and the hydraulic engineers had to do more work to change their design to accommodate this suggestion. As a result, this idea didn't take off because the owners didn't want to pay for re-design. This also added costs associated with changed time constraints during the project and this meant they were reluctant. It is now commonly done and it is proven to save a lot of money in the long run

Again, a conservative mind-set challenges the extant desire to innovate and was shown to restrict, or impede, innovation adoption. In terms of Disruptive Thinking that type of innovation mind-set is not widely disruptive and so the impact appears weak. To overcome this, Wisdom et al. (2014) argues strongly for a project manager or chief innovation officer in companies to have a disruptive view so that innovation is accepted and implemented and thus benefits accrue. Wisdom is perhaps suggesting the need for a broader disruptive mindset. Another respondent, Company Director (D1) said as an example:

a building with a 6 star energy efficiency
(building design as an innovation) is
actually not that expensive compared to any
other building. The design is the key and the
most important element. The building cost is
not that much more, maybe the design cost
was. Maybe it is clients who don't have the
willingness to pay for the design.

The interviewees all noted that the cost of capital investment in innovations in buildings are usually very high. Most of the time the benefits of that innovation in construction can be quite difficult to quantify whether in per unit format or per project, especially in large construction projects. It is also common that many construction projects are oneoff. Another respondent, a principal structural engineer (E1) in reference to specific structure innovative building design in certain types of building application noted that:

capital costs sometimes are not the most important, compared to the whole of life costing. Sometimes you can spend money up front and can save along the line, particularly, in a project like a hospital or a university. In addition, E1 noted: only 10-20\% of our clients are considering the operational cost of long-term assets". Benefits for end-users 'are not considered.

A number of the respondents noted that comparison between projects is often subjective. Costs of innovation from previous projects can be used only as a reference, but not as a benchmark, to compare against. Consideration of any innovation is also often difficult to convert into price per 
unit. In many infrastructure projects, innovation also cannot be quantified. This is unlike any other innovation where the price per unit is low and anyone can pay for a trial, even if it doesn't work the users still can move on. This effect is not an easy aspect for the complexity of stakeholders in the construction industry to understand and then act on. In construction, business value is very high, and stakeholders need some sort of assurance that the innovation would work before they can/will try. Also, the nature of perceived innovation in the construction industry is often unique, ie, bespoke for a specific project unlike other innovations/ products in other consumable markets. It is difficult for end users to measure benefits or perceived benefit of "a building". This benefit or perceived benefit is often linked to innovation used in the building, if they know what the innovation is, or if they 'believe' the commercial advertising for the building. It can be argued that end user views toward innovation can be blurred, distorted or even misunderstood, a point noted by many of the interviewees. A mindset of wanting to implement an innovation often, these responses suggest, are contested by contrary perspectives grounded in different information and / or different mindsets. Another key issue highlighted by the respondents was that the various stakeholders' ability to see apparent change as a result of innovation adoption is often low. It is common for many innovations to take too long for all stakeholders to perceive the benefits.

\section{3) Acceptance of Risk: Capability}

Different construction project sizes determine the length of construction process and any change from an innovation can take 2-3 years before it is even seen. One respondent noted that there was also time needed to see and then measure, if possible, real change or real effect that can emerge from the innovation. Whilst their thinking might be disruptive, adoption and implementation is at best incremental. Similarly, product innovation in the construction industry can often only demonstrate performance after the construction process is finished and the product starts working. This might take years in some cases. This means that the investment has to remain in 'the assets column' for quite a long period of time. These changes are not fast enough to be considered as disruption by Disruption Theory, yet they represent real Disruptive Thinking. Sometimes, the benefit is too difficult to quantify and measure. In the case of process innovation, relevant stakeholders such as builders might be only group who can see the benefit. A manager of an engineering consulting firm (E5) described how his company has a strategy which offers innovation as part of their services to differentiate themselves within the market. One current project that this company has put considerable resources into was to offer a digital building management system (as a service innovation to their clients) to help clients better manage construction projects. It is currently into "the nurturing process" and E5 noted,

we don't know whether it is going to work. We put a lot into it. Hopefully, it will work. Then we can ask the client to be out profiling our showcase to gain some more clients in the future. However, this is a long process. Our firm is a worldwide company. We learn a lot from other offices around the world. The company has a clear goal that we want to be leader in engineering innovation. That's the clear message from the board.

This can be argued to represent Wisdom et al. (2014) innovative thinking, but is it disruptive? Even this company director noted they had taken that risk to put an innovation in, but they don't know the outcome yet. Time then it appears plays a key role in determining if some innovation is disruptive. How long then is the time to determine disruption? There appeared to be no consensus amongst the interviewees. This point was also made by another builder (D3) who noted that:

an innovation such as OSM (as a products and process innovation)... I think the reason that it is not working here (Australia) fully is because there is reluctance to use it. There hasn't been a number of good examples yet. I believe that OSM might catch on certainly in some type of projects, into the future. Again, I think this is a bit of a mind shift but 
it still general construction work that applies differently.

The achievement of fast profit in the short term (Schumpeter's rent) is argued by Sampere (2017) and Gajendran et al. (2014) to create adoption incentives. This research is showing that these incentives are diminished when outcomes are slow to realise, even if they are based initially on Disruptive Thinking.

It is common that products or process innovation are most often introduced to the market by suppliers, not usually by designers, architects or builders. Suppliers often spend time and effort in their research and development process on such innovations. A problem identified by the respondents is that most users, including owners don't want to be 'a guinea pig' to test new innovations. The nature of the construction industry requires the building to work as stated in its design and specifications. Therefore, there is no room for error. Innovation is considered risky, the respondents noted. They also highlighted another problem in that suppliers often only supply single products, but other stakeholders who have to make it work and integrate it are builders. The respondents noted that many times builders or contractors are not willing to accept liability for new product innovation, as they are not familiar with the product. The companies who supply the innovation also cannot take liability because they are not the ones responsible for construction. Many times, the interviewees also noted, innovations are included in a project's specification by architects who might have no technical knowledge and builders are unable to make it work. The intent is disruptive, but this is contested by traditional mindsets and accepted norms in practice.

The engineering and construction industries are grounded in evidence-based practice (Hamilton, 2003; Simmons, 2015). Therefore, any change that is to be introduced to practice often needs to be proven before it can be adopted. The construction industry also operates at a high level of certainty (Mochitele and Wright, 2015). When adopting some form of Disruptive Thinking and trying new innovations, products, or methods, if it is not absolute certain, practitioners often will not take the risk. Often in the interviews the professionals noted that it was common to hear, "If it is not broken, don't fix it". This mind-set might also be one reason that contributes to slow or even incremental uptake of innovation. It can be argued that this concern affects any sense of thinking about or accepting a disruptive innovation. One Engineer (E2) said:

It looks to me like only a big company that has the ability to try all of these new innovations. It is expensive. It is difficult ... If it works... fine make money and lead the industry. If it doesn't work, only they can have financial stability to get back on track and move on and still remain in the industry.

Many subcontractors do not have the financial risk absorbing capacity to take on products and process innovation. E6 added:

as an engineering consultant firm we have put a lot of work into $R \& D$ and innovation. $I$ think tier 1 and maybe tier 2 builder companies have the ability and capability to move forward, try something new. But the construction industry is large. I don't believe that tier 3 down to small size, especially subcontractors, are ready for this yet. They are still doing things their way. They are not ready for this yet. They don't want to take the risk if those innovations aren't work

There is a common thread evident in the practitioner stories that financial implications are seen as one of the factors that hinders practitioners from doing things in new ways. This is because there are always cost implications associated with "what if it doesn't work".

\section{4) Complex Regulation}

The slow adoption of innovation can also result from problems associated with complex regulations. One Australian quantity surveyor (QS3), in relation to a new business model integrated into building design as a building design innovation, stated that: 
to make innovation work you have to work your way through so many layers of a project's organisation and bureaucracy. Not just only in your company but outside as well. For example, to put some children's visiting section in an aged care facility, you have to somehow demonstrate to the clients that it is economically feasible. Even a large amount of research shows that to create a family-like environment surrounding agedcare residents can psychologically help them make them feel like they are still part of the community, and once their mind is in good shape, their health also improves. However, that is difficult to quantify ... Having a children's visiting section means you have to get all sorts of approvals from the council. If you want to attach a cafe into an aged care facility, you also have to go through another whole lot of permissions. It appears to me that everyone has their own agendas, and make the process is so difficult. Again, you have to have a lot of energy to go through all these filters.

One of the engineering firm directors interviewed (D4) said:

it is difficult to identify disruptive innovations in the construction industry. Maybe the digital way of doing things, but it is still difficult to pinpoint, or maybe off-site or affordable housing could be considered. Because it is very difficult to identify maybe that's why the adoption is so low. But as humans, we still want bespoke projects. We don't want everything that looks the same. Most innovations such as OSM that have taken off happened only in projects with high volume from the process point of view. Many other construction projects are still too somewhat one-off (sic). Maybe something like Ikea buildings with standard parts that can be put together into hundreds of designs that look different could become a disruptive innovation.

D4's statement highlights the complex interrelated set of issues involved in innovation adoption in construction from the perception of professionals involved in their adoption. Rather than perceiving innovation adoption as a check list of drivers or motivators or barriers, as reported in the reviews of innovation adoption in the extant literature (Bogers et al., 2017; Wisdom et al., 2014), the construction professionals interviewed in this research report a more complex situation. Whilst there are examples of mindsets using Disruptive Thinking, that is often contested by normative mindsets grounded in, and constrained by, risk aversion to failure, by the potential negative impact of cost overruns, and even project failure. The stories of the construction and engineering professional in this research show there are two parallel mindsets evident in those stories - a mindset informed by Disruptive Thinking and a mindset informed by the status quo.

\section{Discussion}

This paper began by asking: To what extent is a Disruptive Thinking mindset present in professionals in the construction and engineering industry and what affects the use of Disruptive Thinking by those professionals in innovation adoption? Understanding that Disruptive Thinking can be defined on four principles, this research shows that four of those principles [difference], [realistic approach], [complexity], [uncertainty] played some part in both professionals thinking about adopting an innovation and in influencing decision about innovation adoption by professionals working on construction and engineering projects. The key principle for using DT is "difference", but that difference is contextualised in existing practice by realism, complexity and uncertainty, which can be seen to represent the hierarchical and structural aspects of the construction and engineering industries. The professionals interviewed showed that there was a disruptive mindset for change present; for example, their stories related to the use of digital building management system, 6 star energy rating design schemes, the adoption of OSM etc. However, whilst that mindset was evident, their decisions were often challenged by a corresponding mindset of normative practice, reflective of what the existing literature tells us about barriers to innovation adoption. This research 
exposes a contest between the desire to be different versus what the industry as a whole will accept, identified within the mindsets of practitioners in construction and engineering projects.

In construction and engineering projects innovation occurs as a diffusion process, being slow, methodical, reliant on pathways and ordered. In projects without or even with some disruptive thinking, radical change fails because true disruption must offer something that is so different that the traditional constraints/barriers which exist within the construction and engineering fail. True disruption fills a market niche not identified in the existing practice. True disruption occurs in markets not foreseen or expected. The evidence from the interviews in this research shows that while they were instances of disruptive thinking, the impact was never strong enough to be "something so different", or to fill an "identified market niche", or be "stimulated by unforeseen circumstances". Rather any disruptive thinking was diluted by conventional marketplaces, by entrenched norms, and by an apparent lack of foresight about new markets.

The research shows that innovation adoption in their practice was aligned more with the general acceptance of the status quo as the norm, despite their reflective recollections of thinking in what can be accepted as Disruptive Thinking; with the fragmented uptake caused when innovations are differentially applicable to some, but not all, situations and stakeholders; with limited capability to accept risk; and with regulations that create too much complexity. Identification of these issues demonstrated both some use of Disruptive Thinking in innovation adoption in their context but also showed that innovation becomes a zero-sum problem, i.e. it becomes one or the other. Fornstedt et al. (2015) was cited earlier arguing that Disruptive Thinking can be used as a lens to better understand why the acceptance of innovation is often challenged by the status quo or the conservatism inherent in the marketplace. This research would suggest support for that argument.

The stories of practitioners in this research highlighted that where innovation, albeit small, happens, it happens within sub-systems of the construction and engineering industry. For examples, one of the practitioners told the story of an engineering firm that offer digital building management system as part of their design service package which is unique only to their clients. This specific innovation was not available across the construction industry. That practitioner noted this innovation affected only their individual organisation and they didn't see that as innovation across the whole industry. Their mindset of Disruptive Thinking in this instance was individualised, rather than industrialised.

What was also evident in the research is that while Disruptive Thinking is part of what these professionals do, they were specifically challenged by uncertainty embedded in the norms of construction and engineering practice. There is little evidence in this research that an organisational "innovation narrative" (Sergeeva, 2014) was strong enough to create a collective inter-subjectivity of innovation, rather there is a stronger narrative used as a tool to maintain legitimacy of the status quo. In other industries (retail, services, product development) there is substantial evidence of success based on Disruption Thinking, despite the existence of uncertainty. In Medicine and the Law, evidence-based practice is also the norm to address uncertainty. However, when evidence comes from both inhouse and / or collaborative professional and academic research the uncertainty is significantly reduced and ensures adoption of innovation. The construction professionals interviewed here show that adoption of innovation needs the same certainty that adoption will accrue real benefits. However, without demonstrated benefits accruing through evidence-based practice, adoption becomes more problematic because of risk issues and the fragmentation of the industry. It can then perhaps be argued that adoption of practice-based and collaborative practitioner / academics-based research on innovation development or adoption might become a means to strengthen the influence of a Disruptive Thinking mindset in their contest with the extant traditional mindset.

In Medicine and the Law innovations do become integral to their advancement, but they are patient (long term thinkers) and accept innovation as part of an embedded cultural practice (Tucker, 2009). The research re-demonstrated that the 
construction industry is still successfully using its traditional materials, processes and methods and any use of Disruptive Thinking as part of innovation adoption is continually contested by the existing mindset of normative practice. There is no embedded culture of Disruptive Thinking demonstrated in this research in the construction and engineering professionals interviewed. In ways similar to innovation adoption in other industries, this research is showing that utilising a new way of thinking about improvement can facilitate better materials, better processes and better methods. Yet that improvement remains incremental. There is still a remaining complexity created by the fragmented hierarchies with multiple stakeholders across almost all projects which challenge the possibility for Disruptive Thinking.

In answering both of the questions posed at the start, this research shows that whilst there is evidence of use of Disruptive Thinking by the construction professionals, their stories show that their actions in construction and engineering are still grounded in traditional practice and financial risk assessment. They reinforced a common perception in the construction and engineering literature that maintenance of the status quo in their professional practice was the norm. However, they did identify on numerous instances in their stories that innovation offered the potential to be different [difference]. In other instances, they described the impact that complexity has as an inhibitor in their attempts at adopting BIM or OSM [complexity]. Their stories also show that even if they want to be different, or be innovative, it is difficult. For example, a number of the construction professionals described how it was common that conventional procurement practice [realistic approach] of the design-bid-build process was difficult to rethink in terms of 'making a difference' because there was a difficulty where the benefits are difficult to fully realise as there is a question about who will actually benefit when some parties involved in the process are not identify until the later stage [uncertainty]. Their mindset was generally normative. The research then shows that a normative mindset dominates even when a disruptive mindset plays a role in construction and engineering project decision-making about innovation adoption.

\section{Conclusion}

The stories of the practitioners in this research shows that Disruptive Thinking, as defined here (von Mutius, 2017), can be a means to innovation adoption, only if an extant mind-set of evidencebased practice can be infiltrated. The stories of the construction professionals show that they were focused on rationality and the incisiveness of factor or issue thinking, and therefore less attention was paid to directing their focus to new ways of engaging the problem, even if they had thought about adoption of new innovations. Innovation adoption then became focused on subsystems of projects or practice, or became incremental over time through a more diffusive process. Innovations that are not disruptors, according to either Christensen (2006) or Sampere (2017) and others, have limited chance of adoption in the short term when this is the case. The professional interviewed for this research show, that if Disruptive Thinking as a mindset has an effect, that effect is long term, incremental and slow.

The analysis of the practitioners' stories also highlights that there is significant discontinuity due to the project-based nature of their work. Moving from project to project often requires different sets of knowledge and skills and technologies. Winch (2014) argues for project-based firms to adopt "base-moving projects" (Brady and Davies, 2004; Davies, 2004) where the focus is across a number of projects and where repeatable solutions (Davies and Brady, 2000; Prencipe and Tell, 2001) are possible. Disruptive Thinking could potentially enable the transfer of innovations across projects. The extent to which this happen needs to be further explored.

The research shows that the use of Disruptive Thinking by professionals in innovation adoption in construction and engineering is affected by the demands of complexity, their reliance on a continual realistic approach, trying to be risk averse to address uncertainty and being wary of difference. Collectively these issues dampen both their ability and their desire to change, their expectation about being different, their ability to address uncertainty and their wanting to change their practice. These together are the very issues that need to be addressed to enable Disruptive 
Thinking. The stories reported by the professionals in this research highlight the existence of two mindsets, one disruptive and one traditional. The research would suggest that the latter dominates. However, practice in other domains shows that practitioner-based and practitioner-academic collaboration research can enable faster, more effective innovation adoption.

The contribution of this research is varied. Firstly, there is evidence that Disruptive Thinking exists. It is limited and any use of Disruptive Thinking is challenged by extant traditional mindsets. Reluctance to adopt innovations in construction and engineering projects is shown in this research to be more than just barriers we already know from existing research. Rather, reluctance to adopt innovations happens because those barriers dominate thinking processes because those practitioners interviewed here do not have understanding as to how Disruptive Thinking might dominate. Research in other domains show that research, either as collaboration or as practitioner-based research, can enable Disruptive Thinking. However, because of isolation practises in construction and engineering, because of fragmentation in both construction and engineering projects and because of the episode nature of project design and implementation, that necessary nexus between practitioners and research and the exploration of the use of Disruptive Thinking is interrupted.

The contribution of this research to theory also lies in the identification of those practices that are integral to construction and engineering professionals that would enable Disruptive Thinking to occur. Research in Medicine, the Law and Retailing about the use of disruptive mindsets shows that fundamentally practise has to become inclusive of research and new ideas to enable innovation to be adopted. In this research the practitioners themselves talk about innovations they have used, or they have adopted, but they continually think of these innovations as small changes which they have borrowed, and as incremental changes. In the research in the other domains, the Disruptive Thinking is front of mind rather than back of mind. The stories of the practitioners here show that their focus in innovation adoption is on an individualistic rather than industry wide approach. It can be argued that, enabling that focus / practice to include broader perspectives than the individual and subsystems approaches identified in this research, would most probably facilitate more extensive inclusion of Disruptive Thinking. Professional development and university training offer pathways to achieve this. Where the professionals displayed some form of application of Disruptive Thinking in their stories about their decision making, the focus / practice was essentially long term rather than short term. This research shows that this practice emerged as the professionals utilised some forms of Disruptive Thinking to adopt innovation, even if they were embedded in only part of the practice or in some subsystem of the wider professional practice, including industry wide. This practice too could be addressed through changing practice through professional development. Theorising about the practitioner's mindsets to innovation adoption suggests two propositions: 1, that innovation adoption for practitioners is fundamentally driven by more individualistic rather than the industrial concerns; 2, that adopting elements of Disruptive Thinking creates a longer-term focus on the utility of the innovation. These propositions are just that, and need further research.

One contribution of this paper to practice is that Disruptive Thinking offers the potential for practitioners to view adoption of innovation beyond the context of their own practice into broader industrial practice. This would enable a broader diffusion of new ideas. Within the stories of the professionals interviewed there was evidence that innovations were just some small part of a projects and as a result their important was diminished, in comparison to a domain like Medicine where small improvements are celebrated and publicised. In Retailing the use of EFTPOS revolutionised payment systems, albeit that innovation was initially a small change in one retailer.

This paper is an example of narratives captured from small number of practitioners in the construction industry. The research does not intend to generalise the root cause of the slow innovation uptake in the construction industry. The study uses the concept of Disruptive Thinking to 
examine a potential alternative frame of reference for construction practitioners in their work and point out that innovation uptake problem has multidimensions not just the innovation itself. Disruptive Thinking is one of the dimensions that construction practitioners need to reflect upon if we really want to be innovative in this industry, building upon their traditional practice.

Understanding better how some C\&E professional think about innovation as interpreted through the lens of DT has enabled a better understanding of what is happening. The research shows that professionals think about innovation, not simply as checklists of barriers and drivers, but rather within a complex process where Disruptive Thinking principles are used (albeit subconsciously) some of the time as one part of thinking about adoption. However, the research also shows that the extent of this Disruptive Thinking within professionals' actions with regard to innovations was challenged through continual contestation with normative thinking within the industries. This suggests that to improve innovation adoption there needs to be strategies to overcome the embedded strengths in the normative thinking inherent in most construction and engineering projects.

\section{Limitations}

There is an obvious impact on the conclusions drawn here based both on the geographical focus in Australia and on the small sample used in the interviews, quite normal in qualitative research. However, the conclusions drawn offer a set of four issues that could possibly be modelled and tested in much larger quantitative survey-based studies. Such research should enable greater confidence in the conclusions and enable better theorization when tested in different locations. There is also an issue that the finding also needs to be tested across a variety of a construction market and in different contexts. Whilst the respondents in the research were from practitioners with experience in construction and engineering in Australia, the UK and Asia, the research was exploratory and to assess the relevance to other construction marketplaces would require the conclusions derived here to be re-tested. This research addressed the term innovation from a more general perspective accepting innovation could be a product, a process or innovation can be transformation or can apply to organisation or can be considered purely technological. The findings here do not address those specifics. Each type of innovation could in the future be assessed in future research against the more general findings of this paper.

\section{Future Research}

Extending the conclusions reached in this paper and to address the limitations noted above, a much larger research project should now try and better understand what will create a perspective about innovation in construction and engineering that is "so different". We need to understand more about unfilled niche markets in construction and engineering and we need to be able to better use forecasting, transformative modelling and initiate research taking disruptive innovation from other knowledge domains. Much of this will require researchers to actively engage with construction and engineering professionals to undertake collaborative projects in similar ways to medical sciences. We need to better understand how "Futurists" can be utilised in developing and implementing innovations in construction and engineering. Finally, we need to do research to better understand how we can train future construction and engineering professionals and how we can offer training to existing professionals that challenges their mindsets.

\section{References}

Aarons, G.A., Hurlburt, M. and Horwitz, S.M. (2011), "Advancing a conceptual model of evidence-based practice implementation in public service sectors", Administration and Policy in Mental Health and Mental Health Services Research, Vol. 38 No. 1, pp. 4-23. 10.1007/s10488-010-0327-7

AIB. (2017), Standard for the Accreditation of Building \& Construction Management Program (AIB 2017). Australian Capital Territory: Australian Institute of Building.

Akintoye, A. and Main, J. (2012), "Innovation through collaborative procurement strategy and practices". Construction Innovation and Process Improvement. USA: Wiley-Blackwell. pp. 251-276. 
. and Allen, C. and Shakantu, W. (2016), The BIM Revolution: A Literature Review On Rethinking The Business Of Construction. vol. 204. UK: WIT Transactions on Ecology and the Environment. pp. 919-930.

Atuahene, B.T., Kanjanabootra, S. and Gajendran, T. (2020), "Benefits of Big Data Application Experienced in the Construction Industry: A Case of an Australian Construction Company In", Paper presented to Proceedings of the 36th Annual ARCOM Conference.

Australian Institute of Architects. (2017), “Architecture", available at: http://www.architecture.com.au [15 March 2017].

Australian Institute of Quantity Surveyors. (2017), "Member Centre", available at: https://www.aiqs. com.au/imis/AIQS_Website/Membership_Centre/ Member_Grade/AIQS_Website/Public/Membership_information/Member_Grade.aspx [15 March 2017].

Baltar, F. and Brunet, I. (2012), "Social research 2.0: virtual snowball sampling method using Facebook', Internet research", Vol. 22 No. 1, pp. 57-74.

Bekefi, T. and Epstein, M. (2017), "Is your innovation strategy ready to meet the 21 st century?" The European Business Review, Vol. 2017, pp. 39-43.

Biernacki, P. and Waldorf, D. (1981), "Snowball sampling: problems and techniques of chain referral sampling", Sociological Methods \& Research, Vol. 10 No. 2, pp. 141-163. 10.1177/004912418101000205

Blayse, A.M. and Manley, K. (2004), "Key influences on construction innovation", Construction Innovation, Vol. 4 No. 3, pp. 143-154. 10.1108/14714170410815060

Boer, H. and During, W.E. (2001), "Innovation, what innovation? A comparison between product, process and organisational innovation", International Journal of Technology Management, Vol. 22 No. 1-3, pp. 83-107. 10.1504/IJTM.2001.002956

Bogers, M., Zobel, A.-K., Afuah, A., Almirall, E., Brunswicker, S., Dahlander, L., Frederiksen, L., Gawer, A., Gruber, M., Haefliger, S., Hagedoorn, J., Hilgers, D., Laursen, K., Magnusson, M.G., Majchrzak, A., McCarthy, I.P., Moeslein, K.M., Nambisan, S., Piller, F.T., Radziwon, A., Rossi-Lamastra, C., Sims, J. and Ter Wal, A.L.J. (2017), "The open innovation research landscape: established perspectives and emerging themes across different levels of analysis", Industry and Innovation, Vol. 24 No. 1, pp. 8-40. 10.1080/13662716.2016.1240068
Brady, T. and Davies, A. (2004), "Building project capabilities: from exploratory to Exploitative learning", Organization Studies, Vol. 25 No. 9, pp. 1601-1621. 10.1177/0170840604048002

Brewer, G., Gajendran, T. and Le Goff, R. (2012), "Contextualising innovation in construction firms in regional areas", Management, Vol. 1175, p. 1184.

Brockmann, C., Brezinski, H. and Erbe, A. (2016), "Innovation in construction megaprojects', Journal of Construction Engineering and Management", Vol. 142 No. 11, p. 04016059.

Burt, G. (2007), "Why are we Surprised at surprises? integrating disruption theory and system analysis with the scenario methodology to help identify disruptions and discontinuities", Technological Forecasting and Social Change, Vol. 74 No. 6, pp. 731-749. 10.1016/j.techfore.2006.08.010

Bygballe, L.E. and Ingemansson, M. (2014), "The logic of innovation in construction", Industrial Marketing Management, Vol. 43 No. 3, pp. 512-524. 10.1016/j.indmarman.2013.12.019

Chan, P.W. (2013), "Queer eye on a 'straight' life: deconstructing masculinities in construction", Construction Management and Economics, Vol. 31 No. 8, pp. 816-831. 10.1080/01446193.2013.832028

Christensen, C.M. (2006), "The ongoing process of building a theory of disruption', Journal of Product Innovation Management", Vol. 23, , No. no. 1, pp. 39-55.

Christensen, C.M. (2013), The innovator's dilemma: when new technologies cause great firms to fail Harvard Business Review Press.

Christensen, C.M., Baumann, H., Ruggles, R. and Sadtler, T.M. (2006), "Disruptive innovation for social change", Harvard Business Review, Vol. 84 No. 12, 94.

Christensen, C.M., Craig, T. and Hart, S. (2001), "The great disruption'", Foreign Affairs, pp. 80-95.

Christensen, C.M., Hall, T., Dillon, K. and Duncan, D.S. (2016), "Know your customers' jobs to be done", Harvard Business Review, Vol. 94 No. 9, pp. $54-62$.

Coyne, I.T. (1997), "'Sampling in qualitative research", Purposeful and theoretical sampling; merging or clear boundaries?', Journal of Advanced Nursing, Vol. 26 No. 3, pp. 623-630.

Davies, A. (2004), "Moving base into high-value integrated solutions: a value stream approach", Industrial and Corporate Change, Vol. 13 No. 5, pp. 727-756. 10.1093/icc/dth029

Davies, A. and Brady, T. (2000), "Organisational capabilities and learning in complex product systems:

Engineering Project Organization Journal

(C) 2021 Engineering Project Organization Society www.epossociety.org 
towards repeatable solutions", Research Policy, Vol. 29 No. 7-8, pp. 931-953. 10.1016/S00487333(00)00113-X

Denning, S. (2015), “How Useful Is Christensen's Theory Of Disruptive Innovation? Forbe", available at: http://www.forbes.com/sites/stevedenning/2015/10/ 15/how-useful-is-christensens-theory-of-disruptiveinnovation/\#101121834fb7 [30 November 2016].

Denzin, N. and Lincoln, Y. (1994), "Lincoln. Y". Handbook of Qualitative Research. Thousand Oaks, CA, US: Sage Publications Inc.

Dewar, R.D. and Dutton, J.E. (1986), “The adoption of radical and incremental innovations: an empirical analysis", Management Science, Vol. 32 No. 11, pp. 1422-1433. 10.1287/mnsc.32.11.1422

Dubois, A. and Gadde, L.-E. (2002), "The construction industry as a loosely coupled system: implications for productivity and innovation", Construction Management and Economics, Vol. 20 No. 7, pp. 621-631. 10.1080/01446190210163543

Ellett, M.L.C., Beausang, C.C. and Merriam, S.B. (2002), "Introduction to qualitative research", Gastroenterology nursing : the official journal of the Society of Gastroenterology Nurses and Associates No. , Vol. 25 No. 1, pp. 1-17. 10.1097/00001610200201000-00004

Emerson, R.W. (2015), “Convenience sampling, random sampling, and Snowball sampling: how does sampling affect the validity of research?" Journal of Visual Impairment \& Blindness, Vol. 109 No. 2, pp. 164-168. 10.1177/0145482X1510900215

Engineering Australia. (2017), available at: https:// www.engineersaustralia.org.au/Membership/Occupational-Categories; [15 March 2017].

Eriksson, T. and Kadefors, A. (2015), "Designing and implementing incentives for engineering consultants: encouraging cooperation and innovation in a large infrastructure project", Engineering Project Organization Journal, Vol. 5 No. 4, pp. 146-159. 10.1080/21573727.2015.1104664

Feldstein, A.C. and Glasgow, R.E. (2008), “A practical, robust implementation and sustainability model (PRISM) for integrating research findings into practice", The Joint Commission Journal on Quality and Patient Safety, Vol. 34 No. 4, pp. 228-243. 10.1016/ S1553-7250(08)34030-6

Fellows, R.F. and Liu, A. (2015), Research methods for construction. USA: John Wiley \& Sons.

Fereday, J. and Muir-Cochrane, E. (2006), "Demonstrating rigor using thematic analysis: a hybrid approach of inductive and deductive coding and theme development", International Journal of
Qualitative Methods, Vol. 5 No. 1, pp. 80-92. 10.1177/160940690600500107

Flamholtz, E.G. and Randle, Y. (2014), Implications of organizational life cycles for corporate culture and climate. UK: The Oxford handbook of organizational climate and culture. pp. 235-256.

Fornstedt, H., Lindahl, M. and Sköld, D. (2015), "Stalling Innovation Adoption through the Emergence of Neoconservative Market Structures: Observations from the Energy Sector", Paper presented to 22ND Innovation \& Product Development Management Conference.

Frambach, R.T. and Schillewaert, N. (2002), "Organizational innovation adoption: a multi-level framework of determinants and opportunities for future research", Journal of Business Research, Vol. 55 No. 2, pp. 163-176. 10.1016/S01482963(00)00152-1

Fukiyama, F. (1999), The Great Disruption: Human Nature and the Reconstitution of Social OrderJSTOR. pp. 0098-7921.

Gajendran, T., Brewer, G., Gudergan, S. and Sankaran, S. (2014), "Deconstructing dynamic capabilities: the role of cognitive and organizational routines in the innovation process", Construction Management and Economics, Vol. 32 No. 3, pp. 246-261. 10.1080/01446193.2013.845306

Gann, D.M. and Salter, A.J. (2000), "Innovation in project-based, service-enhanced firms: the construction of complex products and systems", Research Policy, Vol. 29 No. 7-8, pp. 955-972. 10.1016/ S0048-7333(00)00114-1

Geertz, C. (1973), The interpretation of cultures: Selected essays. vol. 5019. New York: Basic books.

Graham, I.D. and Logan, J. (2004), "Innovations in knowledge transfer and continuity of care", The Canadian journal of nursing research $=$ Revue canadienne de recherche en sciences infirmieres, Vol. 36 No. 2, pp. 89-103.

Hall, D.M., Whyte, J.K. and Lessing, J. (2020), "Mirror-breaking strategies to enable digital manufacturing in silicon Valley construction firms: a comparative case study", Construction Management and Economics, Vol. 38 No. 4, pp. 322-339. 10.1080/01446193.2019.1656814

Hall, N.G. (2012), "Project management: recent developments and research opportunities", Journal of Systems Science and Systems Engineering, Vol. 21 No. 2, pp. 129-143. 10.1007/s11518-012-5190-5

Hamilton, D.K. (2003), "The four levels of evidencebased practice", Healthcare Design, Vol. 3 No. 4, pp. 18-26.

Engineering Project Organization Journal

(C) 2021 Engineering Project Organization Society www.epossociety.org 
Holt, G.D. and Edwards, D.J. (2013), “Interorganizational interactions among a sample of plantreliant construction sub-contractors", Engineering Project Organization Journal, Vol. 3 No. 2, pp. 100-115. 10.1080/21573727.2012.760156

Hunhevicz, J.J. and Hall, D. (2020), “Crypto-Economic Incentives in the Construction Industry", ]aper presented to ARCOM Doctoral Workshop; Exploring the mutual role of BIM, Blockchain and IoT in changing the design, construction and operation of built assets, Newcastle, UK.

Irizarry, J. and Costa, D.B. (2016), "Exploratory study of potential applications of unmanned aerial systems for construction management tasks", Journal of Management in Engineering, Vol. 32 No. 3, p. 05016001. 10.1061/(ASCE)ME.1943-5479.0000422

Kanjanabootra, S. and Corbitt, B. (2016), "Reproducing knowledge in construction expertise: a reflexive theory, critical approach", Construction Management and Economics, Vol. 34 No. 7-8, pp. 561-577. 10.1080/01446193.2016.1151064

Katsonis, M. and Botros, A. (2015), "Digital government: a primer and professional perspectives", Australian Journal of Public Administration, Vol. 74 No. 1, pp. 42-52. 10.1111/1467-8500.12144

King, A.A. and Baatartogtokh, B. (2015), "How useful is the theory of disruptive innovation?', MIT Sloan management review”, Vol. 57 No. 1, p. 77.

Lansley, P.R. (1987), "Corporate strategy and survival in the UK construction industry", Construction Management and Economics, Vol. 5 No. 2, pp. 141-155. 10.1080/01446198700000013

Lee, B., Carpenter, C.R., Neta, G., Glasgow, R.E., Rabin, B.A. and Brownson, R.C. (2015), "STORYTELLING to enhance the value of RESEARCH/ CARPENTER et al respond", American journal of public health, Vol. 105 No. 4, E1.

Li, Y. and Liu, C. (2019), “Applications of multirotor drone technologies in construction management", International Journal of Construction Management, Vol. 19 No. 5, pp. 401-412. 10.1080/15623599.2018.1452101

Ling, F.Y.Y. (2003), "Managing the implementation of construction innovations", Construction Management and Economics, Vol. 21 No. 6, pp. 635-649. 10.1080/0144619032000123725

Lloyd-walker, B.M., Mills, A.J. and Walker, D.H.T. (2014), "Enabling construction innovation: the role of a no-blame culture as a collaboration behavioural driver in project alliances", Construction Management and Economics, Vol. 32 No. 3, pp. 229-245. $10.1080 / 01446193.2014 .892629$
Löwstedt, M. (2015), “"Taking off my glasses in order to see': exploring practice on a building site using self-reflexive ethnography", Construction Management and Economics, Vol. 33 No. 5-6, pp. 404-414. 10.1080/01446193.2015.1066021

Markides, C. (2006), "Disruptive innovation: in need of better Theory*", Journal of Product Innovation Management, Vol. 23 No. 1, pp. 19-25. 10.1111/j.1540-5885.2005.00177.x

Markides, C. (2013), "Disruptive innovation at the bottom of the pyramid (BOP)". Disruptive Innovation in Chinese and Indian Businesses. vol. 167. UK: Routledge. pp. 167-178.

Miller, C.A., O’Leary, J., Graffy, E., Stechel, E.B. and Dirks, G. (2015), "Narrative futures and the governance of energy transitions', Futures", Vol. 70, pp. 65-74.

Mitchell, S.A., Fisher, C.A., Hastings, C.E., Silverman, L.B. and Wallen, G.R. (2010), "A thematic analysis of theoretical models for translational science in nursing: mapping the field", Nursing Outlook, Vol. 58 No. 6, pp. 287-300. 10.1016/j. outlook.2010.07.001

Mochitele, M. and Wright, D. (2015), "Proposed CIDB regulation amendments: construction law"', Without Prejudice, Vol. 15 No. 9, pp. 69-70.

Mollaoglu-Korkmaz, S., Miller, V.D. and Sun, W. (2014), “Assessing key dimensions to effective innovation implementation in interorganizational project teams: an integrated project delivery case", Engineering Project Organization Journal, Vol. 4 No. 1, pp. 17-30. 10.1080/21573727.2013.855895

Motawa, I. and Kardakou, A. (2018), “Unmanned aerial vehicles (UAVs) for inspection in construction and building industry", Paper presented to The 16th International Operation \& Maintenance Conference.

Mui, C. and Carroll, P. (2013), The new killer apps: how large companies can out-innovate startupsCornerloft Press.

Murphy, M.E., Perera, S. and Heaney, G. (2015), "Innovation management model: a tool for sustained implementation of product innovation into construction projects", Construction Management and Economics, Vol. 33 No. 3, pp. 209-232. 10.1080/01446193.2015.1031684

Nam, C.H. and Tatum, C.B. (1997), "Leaders and champions for construction innovation", Construction Management and Economics, Vol. 15 No. 3, pp. 259-270. 10.1080/014461997372999

OECD, E. (2005), Oslo Manual 2005', Guidelines for Collecting and Interpreting Innovation Data. 3rd edn ed. Paris: .

Engineering Project Organization Journal

(C) 2021 Engineering Project Organization Society www.epossociety.org 
Oyewobi, L.O., Windapo, A.O., Rotimi, J.O.B. and Jimoh, R.A. (2016), "Relationship between competitive strategy and construction organisation performance: the moderating role of organisational characteristics"', Management Decision, Vol. 54 No. 9, pp. 2340-2366.

Ozorhon, B., Abbott, C. and Aouad, G. (2014), “Integration and leadership as enablers of innovation in construction: case study", Journal of Management in Engineering, Vol. 30 No. 2, pp. 256-263. 10.1061/(ASCE)ME.1943-5479.0000204

O'Reilly III, C.A. and Tushman, M.L. (2016), Lead and disrupt: How to solve the innovator's dilemma. USA: Stanford University Press.

Pellicer, E., Yepes, V., Correa, C.L. and Alarcón, L.F. (2014), "Model for systematic innovation in construction companies", Journal of Construction Engineering and Management, Vol. 140 No. 4, p. B4014001. 10.1061/(ASCE)CO.1943-7862.0000700

Pellicer, E., Yepes, V., Correa, C.L. and Alarcón, L.F. (2017), "The dilemma of innovation in the construction company: a decade of lessons learned". Project Management and Engineering Research. Germany: Springer. pp. 21-33.

Polkinghorne, D.E. (2005), "Language and meaning: data collection in qualitative research", Journal of Counseling Psychology, Vol. 52 No. 2, pp. 137-145. 10.1037/0022-0167.52.2.137

Porter, M.E. (2008), "The five competitive forces that shape strategy", Harvard Business Review, Vol. 86 No. 1, pp. 78-93.

Prencipe, A. and Tell, F. (2001), "Inter-project learning: processes and outcomes of knowledge codification in project-based firms", Research Policy, Vol. 30 No. 9, pp. 1373-1394. 10.1016/S00487333(01)00157-3

Raynor, M.E. (2011), "Disruption theory as a predictor of innovation success/failure", Strategy \& Leadership, Vol. 39 No. 4, pp. 27-30. $10.1108 / 10878571111147378$

Reichstein, T., Salter, A.J. and Gann, D.M. (2005), "Last among equals: a comparison of innovation in construction, services and manufacturing in the UK", Construction Management and Economics, Vol. 23 No. 6, pp. 631-644. $10.1080 / 01446190500126940$

Rigby, E.T., McCoy, A.P. and Garvin, M.J. (2012), "Toward aligning academic and industry understanding of innovation in the construction industry", International Journal of Construction Education and Research, Vol. 8 No. 4, pp. 243-259. 10.1080/15578771.2012.663861
Rogers, E.M. (2010), Diffusion of innovations. USA: Simon and Schuster.

Rose, T.M. and Manley, K. (2014), "Revisiting the adoption of innovative products on Australian road infrastructure projects", Construction Management and Economics, Vol. 32 No. 9, pp. 904-917. 10.1080/01446193.2014.938670

Sage, D., Dainty, A. and Brookes, N. (2012), “A 'Strategy-as-Practice' exploration of lean construction strategizing", Building Research \& Information, Vol. 40 No. 2, pp. 221-230. 10.1080/09613218.2012.655925

Sampere, J. (2017), "How high-end disruption completes the disruptive innovation model", The European Business Review, Vol. 2017.

Schumpeter, J. (1942), Capitalism, Socialism and Democracy. New York: Harper.

Schumpeter, J.A. (1947), "The creative response in economic history", The Journal of Economic History, Vol. 7 No. 2, pp. 149-159. 10.1017/ S0022050700054279

Sergeeva, N. (2014), "Understanding of labelling and sustaining of innovation in construction: a sensemaking perspective", Engineering Project Organization Journal, Vol. 4 No. 1, pp. 31-43. 10.1080/21573727.2013.869211

Sergeeva, N. and Trifilova, A. (2018), "The role of storytelling in the innovation process", Creativity and Innovation Management, Vol. 27 No. 4, pp. 489-498. 10.1111/caim.12295

Shelton, J., Martek, I. and Chen, C. (2016), "Implementation of innovative technologies in small-scale construction firms: five Australian case studies", Engineering, Construction and Architectural Management, Vol. 23 No. 2, pp. 177-191.

Simmons, R. (2015), “Constraints on evidence-based policy: insights from government practices", Building Research \& Information, Vol. 43 No. 4, pp. 407-419. 10.1080/09613218.2015.1002355

Slaughter, E.S. (1998), "Models of construction innovation”, Journal of Construction Engineering and Management, Vol. 124 No. 3, pp. 226-231. 10.1061/ (ASCE)0733-9364(1998)124:3(226)

Slaughter, E.S. (2000), "Implementation of construction innovations", Building Research \& Information, Vol. 28 No. 1, pp. 2-17. 10.1080/096132100369055

Stake, R.E. (2013), Multiple case study analysis. New York: Guilford Press.

Tucker, M.T. (2009), Application of the diffusion of innovations theory and the health belief model to describe EMR use among Alabama family medicine physicians: A rural and urban analysis. USA: University of Alabama Libraries.

Engineering Project Organization Journal

(C) 2021 Engineering Project Organization Society www.epossociety.org 
von Mutius, B. (2017), Disruptive Thinking: das

Denken, das der Zukunft gewachsen ist. Vancouver: GABAL Verlag GmbH.

Weidman, J.E., Dickerson, D.E. and Koebel, C.T. (2016), "Technology champions: a theory-based intervention to improve adoption of occupational safety innovations", International Journal of Construction Education and Research, Vol. 12 No. 3, pp. 193-207. 10.1080/15578771.2015.1118417

Williams, L. (2015), Disrupt: Think the unthinkable to spark transformation in your business. USA: FT Press.

Winch, G. (1998), “Zephyrs of creative destruction: understanding the management of innovation in construction", Building Research \& Information, Vol. 26 No. 5, pp. 268-279. 10.1080/096132198369751

Winch, G.M. (2003), "How innovative is construction? comparing aggregated data on construction innovation and other sectors - a case of apples and pears", Construction Management and Economics, Vol. 21 No. 6, pp. 651-654. $10.1080 / 0144619032000113708$

Winch, G.M. (2014), "Three domains of project organising”, International Journal of Project Man- agement, Vol. 32 No. 5, pp. 721-731. 10.1016/j. ijproman.2013.10.012

Wisdom, J.P., Chor, K.H.B., Hoagwood, K.E. and Horwitz, S.M. (2014), "Innovation adoption: a review of theories and constructs", Administration and Policy in Mental Health and Mental Health Services Research, Vol. 41 No. 4, pp. 480-502. 10.1007/ s10488-013-0486-4

Wolcott, H.F. (1999), Ethnography: A way of seeing. Lanham: Rowman Altamira.

Wong, Kam-din. and Fan, Q. (2013), "Building information modelling (Bim) for sustainable building design", Facilities, Vol. 31 No. 3/4, pp. 138-157. 10.1108/02632771311299412

Yin, R.K. (1994), "Discovering the future of the case study. method in evaluation research", Evaluation practice, Vol. 15 No. 3, pp. 283-290.

Yusof, Nor'Aini., Mustafa Kamal, E., Kong-Seng, L. and Iranmanesh, M. (2014), “Are innovations being created or adopted in the construction industry? exploring innovation in the construction industry", SAGE Open, Vol. 4 No. 3, p. 215824401455242. $10.1177 / 2158244014552424$ 